\section{The utility of exhaled nitric oxide in patients with suspected asthma}

\author{
ABSTRACT \\ The value of $\mathrm{FE}_{\mathrm{NO}}$ measurements in patients \\ with symptoms suggestive of asthma is \\ unclear. We performed an observational study \\ to assess the ability of $\mathrm{FE}_{\mathrm{NO}}$ to diagnose \\ asthma and to predict response to inhaled \\ corticosteroids (ICS). Our findings suggest \\ $\mathrm{FE}_{\mathrm{NO}}$ is not useful for asthma diagnosis but is \\ accurate at predicting ICS response.
}

\section{INTRODUCTION}

Data suggest that up to $40 \%$ of patients diagnosed and treated for asthma with inhaled corticosteroids (ICS) have no evidence that this treatment is needed. ${ }^{1}$ Overdiagnosis of asthma is common because symptoms of the condition are non-specific ${ }^{2}$ and there are no readily available tests to confidently exclude asthma.

Proposed National Institute for Health and Care Excellence (NICE) guidelines consider measurement of $\mathrm{FE}_{\mathrm{NO}}$ levels in the diagnostic algorithm, ${ }^{3}$ although a recent meta-analysis concluded that the sensitivity and specificity of $\mathrm{FE}_{\mathrm{NO}}$ was insufficient for accurate diagnosis. ${ }^{4}$ An alternative approach for the use of $\mathrm{FE}_{\mathrm{NO}}$ in patients with symptoms suggestive of asthma is to identify individuals who are likely to have $\mathrm{TH} 2$ high inflammation and therefore likely to respond to ICS. ${ }^{5}$

We aimed to establish if $\mathrm{FE}_{\mathrm{NO}}$ measurements can (1) accurately diagnose asthma in patients presenting to primary care and (2) reliably distinguish which patients will benefit from ICS treatment.

\section{METHODS}

Adult patients with respiratory symptoms suggestive of asthma who were thought to require ICS treatment by their general practitioner (GP) were prospectively identified (see online supplementary data).

After consenting to the study (REC12/ EM/0241), participants attended a baseline visit at which $\mathrm{FE}_{\mathrm{NO}}$ (NIOX MINO; Aerocrine, Tolna, Sweden), spirometry, methacholine challenge, sputum induction for sputum cell count, asthma control questionnaire (ACQ) and asthma control test (ACT) were measured and those willing returned the following day for reversibility testing with $400 \mu \mathrm{g}$ salbutamol inhaled via a spacer. Participants then started their GP-prescribed ICS, which was predominantly beclomethasone dipropionate $(200 \mu \mathrm{g}$ twice daily) via a metered dose inhaler, and returned at 4 and 12 weeks for repeat $\mathrm{FE}_{\mathrm{NO}}$, spirometry, methacholine challenge, ACQ and ACT.

Diagnosis of asthma was defined as one or both:

- Reversibility of $\geq 12 \%$ and $\geq 200 \mathrm{~mL}$ in $\mathrm{FEV}_{1}$

- Provocative concentration of methacholine $\left(\mathrm{PC}_{20}\right)$ of $\leq 8 \mathrm{mg} / \mathrm{mL}$

Response to ICS was predefined as a combination of two of any of the following objective criteria or one objective criterion and one subjective criterion from the following predetermined criteria:

Objective:

- Increase in $\mathrm{FEV}_{1}$ from baseline of $\geq 12 \%$

- Increase in $\mathrm{PC}_{20} \geq$ one doubling dose ${ }^{6}$

- Decrease in $\mathrm{FE}_{\mathrm{NO}}$ of $\geq 20 \%$ for baseline values $>50 \mathrm{ppb}$ or decrease of $\geq 10 \mathrm{ppb}$ for baseline values $\leq 50 \mathrm{ppb}^{7}$

Subjective:

- Decrease in ACQ of $\geq 0.5$

- Increase in ACT of $\geq 3$ points

Data were entered into Stata (Statacorp, Texas, USA) and receiver operator characteristics (ROC) analysis was carried out in Stata and GraphPad Prism.

\section{RESULTS}

Seventy-seven participants were included in the study, of whom 74 completed the investigations (see online supplementary data for consort diagram). Demographic details are shown in table 1 . A diagnosis of asthma was made in 28 out of 74 subjects (38\%). Of these, 10 were diagnosed by reversibility criteria alone and 12 were diagnosed by $\mathrm{PC}_{20}$ alone, with 6 being positive on both investigations. The ROC curve to assess the utility of baseline $\mathrm{FE}_{\mathrm{NO}}$ level as a diagnostic test for asthma had an area under the curve (AUC) of $0.62(p=0.09)$ (figure 1).

A response to ICS was seen in 27 out of 67 subjects $(40 \%)$ after 4 weeks and 28 out of 60 subjects $(47 \%)$ after 12 weeks. Of the 28 subjects with asthma, 16 $(57 \%)$ had a response to ICS after 4 weeks, with 12 of them having sustained this response after 12 weeks. Of the nonasthmatic subjects, 11 also demonstrated

Table 1 Demographics and clinical characteristics of subjects with and without asthma

\begin{tabular}{|c|c|c|}
\hline & $\begin{array}{l}\text { Subjects with asthma } \\
\text { Frequency }(\%)\left(\text { except*) }^{*}\right.\end{array}$ & $\begin{array}{l}\text { Subjects without asthma } \\
\text { Frequency (\%) (except*) }\end{array}$ \\
\hline Total no. included for analysis & 28 & 46 \\
\hline Median age (range) & $29(18-70)^{*}$ & $22(18-73)^{*}$ \\
\hline Sex: male & $11(39)$ & $23(50)$ \\
\hline \multicolumn{3}{|l|}{ Ethnic group } \\
\hline Asian or Asian British & $1(3.6)$ & $5(10.9)$ \\
\hline Black or Black British & $4(14.3)$ & $0(0)$ \\
\hline Mixed ethnicity & $1(3.6)$ & $0(0)$ \\
\hline White or White British & $22(78.6)$ & $41(89.1)$ \\
\hline \multicolumn{3}{|l|}{ Smoking history } \\
\hline Current & $5(17.9)$ & $5(10.9)$ \\
\hline Ex-smokers & $4(14.3)$ & $9(19.6)$ \\
\hline Non-smokers & $19(67.9)$ & $32(69.6)$ \\
\hline Positive family history of asthma & $13(46.4)$ & $21(45.7)$ \\
\hline History/symptoms of GO reflux & $5(17.9)$ & $9(19.6)$ \\
\hline History/symptoms of eczema & $4(14.3)$ & $6(13.0)$ \\
\hline History/symptoms of rhinitis & $9(32.1)$ & $8(17.4)$ \\
\hline History/symptoms of hay fever & $12(42.9)$ & $20(43.5)$ \\
\hline History of NSAID allergy & $1(3.6)$ & $1(2.2)$ \\
\hline \multirow[t]{2}{*}{ Positive skin prick for $\geq 1$ aeroallergen } & $17(60.7)$ & $26(56.5)$ \\
\hline & Mean (SD) & Mean (SD) \\
\hline $\mathrm{FEV}_{1} \%$ predicted & $86.7(14.0)$ & $96.9(15.6)$ \\
\hline $\mathrm{FEV}_{1}: \mathrm{FVC}$ ratio $(\%)$ & $76(10)$ & $82.1(8.4)$ \\
\hline Reversibility (\%) & $12.6(11.7)$ & $3.6(6.3)$ \\
\hline Blood eosinophil count $\left(\times 10^{9} / \mathrm{L}\right) \dagger$ & $0.35(0.4)$ & $0.2(0.1)$ \\
\hline Baseline ACQ score & $1.96(0.81)$ & $1.42(0.82)$ \\
\hline Baseline ACT score & $15.8(4.4)$ & $17.2(4.2)$ \\
\hline
\end{tabular}

tData presented are median and IQR as variable not normally distributed.

ACQ, asthma control questionnaire; ACT, asthma control test; GO, gastro-oesophageal; NSAID, non-steroidal anti-inflammatory drug. 

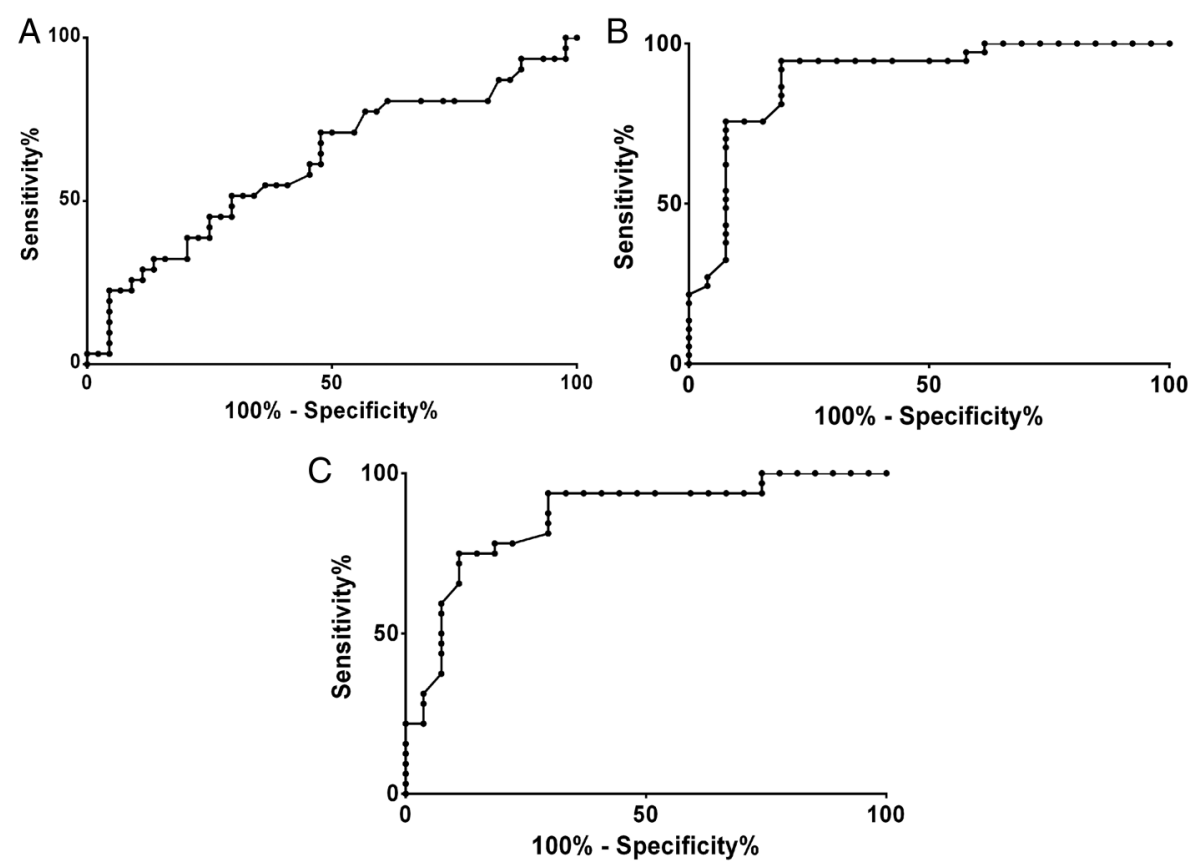

Figure 1 (A) Receiver operator characteristic (ROC) curve analysis showing the sensitivity (\%) and $100 \%$ specificity of $\mathrm{FE}_{\mathrm{NO}}$ levels for asthma diagnosis. (B) ROC curve analysis showing the sensitivity (\%) and the $100 \%$ specificity of $\mathrm{FE}_{\mathrm{NO}}$ levels for predicting inhaled corticosteroids (ICS) response after 4 weeks of ICS treatment. (C) ROC curve analysis showing the sensitivity (\%) and the $100 \%$ specificity of $\mathrm{FE}_{\mathrm{NO}}$ levels for predicting ICS response after 12 weeks of ICS treatment.

a response to ICS after 4 weeks. The ROC curve for baseline $\mathrm{FE}_{\mathrm{NO}}$ level as a predictor of ICS response after 4 weeks had an AUC of $0.89(\mathrm{p}<0.0001)$ (figure 1). The optimal $\mathrm{FE}_{\mathrm{NO}}$ cut-off point for predicting non-response to ICS was $<27 \mathrm{ppb}$ (negative predictive value 93\%) and for predicting response was $>33$ ppb (positive predictive value 92\%). $\mathrm{FEV}_{1}, \mathrm{PC}_{20}$ and blood eosinophil count did not perform as well as predictors of ICS response with AUCs between 0.32 and 0.67 (see online supplementary data).

The ability of $\mathrm{FE}_{\mathrm{NO}}$ level to predict steroid response after 12 weeks was consistent with response at 4 weeks (ROC $\mathrm{AUC}=0.86 \mathrm{p}<0.0001$ ) (figure 1).

\section{DISCUSSION}

Our results suggest that $\mathrm{FE}_{\mathrm{NO}}$ measurement in people presenting to primary care with symptoms suggestive of asthma is more useful at predicting response to ICS than diagnosing asthma. Although our cohort was relatively small we feel our results demonstrate that using $\mathrm{FE}_{\mathrm{NO}}$ to diagnose asthma needs further investigation before being recommended in guidelines.

The poor sensitivity and specificity of $\mathrm{FE}_{\mathrm{NO}}$ in diagnosing asthma may be due to the heterogeneity of the condition with different inflammatory subtypes expressing high or low levels of $\mathrm{TH} 2$ inflammation. ${ }^{5}$ Hence the true utility of this test may be in detecting the presence of underlying $\mathrm{TH} 2$ inflammation to guide appropriate treatment with ICS, as also suggested previously by Smith et al. ${ }^{8}$ The finding that only $57 \%$ of subjects with confirmed asthma responded to ICS further highlights the limitations of this diagnostic label.

Our study was subject to several limitations including the lack of a formal measure of ICS adherence and the definition of asthma and ICS response. Defining asthma is notoriously problematic owing to the lack of a confirmatory gold standard; defining response to ICS is also difficult. Our chosen response criteria are likely to be 'over-sensitive' in detecting a response, but are therefore less likely to miss potential responders. We included a fall in $\mathrm{FE}_{\mathrm{NO}}$ which is not used routinely but was frequently the only objective change in patients with a subjective improvement in cough and has the advantage of being easily performed in primary care. Also, it has previously been established that a reduction in TH2 inflammation is associated with a reduced risk of exacerbations, ${ }^{59}$ bringing some validity to this approach.

We propose that $\mathrm{FE}_{\mathrm{NO}}$ measurement in patients with symptoms suggestive of airways disease could be used to identify patients in whom ICS response is highly unlikely. This could avoid unnecessary ICS treatment and encourage further investigation of the cause of the symptoms and, therefore, more effective treatment.

\section{J Martin, E Wilson, W Gerrard-Tarpey, G Meakin, G Hearson, T M McKeever, D E Shaw, T W Harrison}

Nottingham Respiratory Research Unit, University of Nottingham, Nottingham City Hospital, Nottingham, UK

Correspondence to Dr Matthew J Martin, Nottingham Respiratory Research Unit, University of Nottingham, Room B35, Clinical Sciences Building, Nottingham City Hospital, Hucknall Road, Nottingham NG5 1PB, UK; matthew.martin@nottingham.ac.uk

Twitter Follow Glenn Hearson at @NottinghamRRU

Contributors TWH had full access to all the data in the study, is the guarantor of the content of the manuscript, including the data and analysis, and takes responsibility for the integrity of the data and the accuracy of the data analysis, including any adverse effects. TWH, TMM and EW were co-applicants on the NIHR research for patient benefit grant. MJM, EW and WG-T contributed substantially to data collection. Sputum samples were processed by GM. MJM, EW, GH, TMM, DES and TWH contributed substantially to the study design, data analysis and interpretation and the writing of the manuscript.

Funding This paper summarises independent research funded by the National Institute for Health Research (NIHR) under its Research for Patient Benefit Programme (Grant Reference Number PB-PG-101023145).

Disclaimer The views expressed are those of the author(s) and not necessarily those of the NHS, the NIHR or the Department of Health.

Competing interests None declared.

Ethics approval National Research Ethics Committee East Midlands-Derby 1 (Ref 12/EM/0241).

Provenance and peer review Not commissioned; externally peer reviewed.

- Additional material is published online only. To view please visit the journal online (http://dx.doi.org/10. 1136/thoraxjnl-2015-208014).

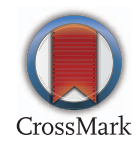

To cite Martin MJ, Wilson E, Gerrard-Tarpey W, et al. Thorax 2016;71:562-564.

Received 4 November 2015

Revised 27 January 2016

Accepted 28 January 2016

Published Online First 22 February 2016

Thorax 2016;71:562-564.

doi:10.1136/thoraxjn-2015-208014

\section{REFERENCES}

1 Lucas AE, Smeenk FW, Smeele IJ, et al. Overtreatment with inhaled corticosteroids and diagnostic problems in primary care patients, an exploratory study. Fam Pract 2008;25:86-91.

2 Lim SY, Jo YJ, Chun EM. The correlation between the bronchial hyperresponsiveness to methacholine and asthma like symptoms by GINA questionnaires for the diagnosis of asthma. BMC Pulm Med 2014;14:161. 
3 National Institute for Health and Care Excellence (NICE). Asthma-diagnosis and monitoring. London, UK, 2015. https://www.nice.org.uk/guidance/ indevelopment/gid-cgwave0640

4 Li Z, Qin W, Li L, et al. Diagnostic accuracy of exhaled nitric oxide in asthma: a meta-analysis of 4,691 participants. Int J Clin Exp Med 2015:8:8516-24.

5 Pavord ID, Shaw DE, Gibson PG, et al. Inflammometry to assess airway diseases. Lancet 2008:372:1017-19.
6 Reddel HK, Taylor DR, Bateman ED, et al. An official American Thoracic Society/European Respiratory Society statement: asthma control and exacerbations: standar-dizing endpoints for clinical asthma trials and clinical practice. Am J Respir Crit Care Med 2009;180:59-99.

7 American Thoracic Society; European Respiratory Society. ATS/ERS recommendations for standardized procedures for the online and offline measurement of exhaled lower respiratory nitric oxide and nasal nitric oxide, 2005. Am J Respir Crit Care Med 2005;171:912-30.

8 Smith AD, Cowan JO, Brassett KP, et al. Exhaled nitric oxide: a predictor of steroid response. Am J Respir Crit Care Med 2005;172:453-9.

9 Powell H, Murphy VE, Taylor DR, et al. Management of asthma in pregnancy guided by measurement of fraction of exhaled nitric oxide: a double-blind, randomised controlled trial. Lancet 2011;378: 983-90. 